ICAMS $2016-6^{\text {th }}$ International Conference on Advanced Materials and Systems

\title{
ANALYSIS OF BIOMECHANICAL PARAMETERS VARIANCE BY WEIGHT FOR ELDERLY WOMEN IN ROMANIA
}

\author{
DANA CORINA DESELNICU ${ }^{1}$, ANA MARIA VASILESCU², MIRELA PANTAZI², \\ GHEORGHE MILITARU ${ }^{1}$ \\ ${ }^{1}$ Politehnica University of Bucharest, 313 Splaiul Independentei, sector 6, Bucharest, Romania, \\ dana.deselnicu@upb.ro,gheorghe.militaru@upb.ro \\ ${ }^{2}$ INCDTP - Division Leather and Footwear Research Institute, 93 Ion Minulescu str., sector 3, \\ Bucharest, Romania, anamariavasilescu@gmail.com, pantazimirela@yahoo.com
}

\begin{abstract}
The paper presents the results of a fieldwork study conducted in order to analyze the variation of different biomechanical parameters of elderly women in Romania. The study has an exploratory and descriptive nature and uses quantitative methodology. The sample consisted of 100 elderly women from Romania, ranging from 55 to over 75 years of age. The collected data was analyzed using a statistic analysis software program. The analysis of variance demonstrated significant differences across weight groups in terms of biomechanical parameters such as toe off phase and support phase in the case of elderly women.
\end{abstract}

Keywords: elderly, biomechanical parameters, force platform.

\section{INTRODUCTION}

Despite their specific needs, old people are currently constrained to accept the mass footwear that they are offered. Because of their foot deformities, their biomechanical characteristics are different than the rest of the population (Deselnicu et al., 2016a) and constitute important indicators for a better understanding and analysis of their particular footwear necessities (Deselnicu et al., 2016b; Deselnicu et al., 2008). The elderly people, with a lot of illnesses caused by age, are mainly disposed to osteopathy (Galasso et al., 2009). In the World Health Organization list of preventive activities, the major place is taken by the relevant orthopedic means, among them choosing and processing the correcting means for the normalization of the deformations of footwear and foot pathologies.

From a mechanical point of view, the human locomotor apparatus represents a complex system of levers acted upon by a force field. The biomechanics studies reveal the nature of these forces, their actions, as well as the loads acting upon the foot and, through it, on the footwear components (Vasilescu et al., 2010). These studies are used for offering information for the rational footwear manufacturing (Deselnicu et al., 2014), in particular, the shape of the insole, sole or heel. Since footwear represents a necessity nowadays (Zainescu et al., 2014), the constructive parameters of the pattern of the footwear product are very important (Mihai et al., 2005).

\section{RESEARCH METHODOLOGY}

The study used the quantitative methodology and an exploratory and descriptive approach. The research methods which best fit the objective of the study were the biomechanical gait measurement for ground reaction force, the questionnaire-based survey, and observation. 


\section{Data Collection}

The data was collected in Bucharest over a period of 3 weeks in November 2015. The ground reaction force was measured using AMTI's AccuGait System (www.amti.biz), with NetForce and NetForce/ BioAnalysis components. The respondents were also applied a short questionnaire consisting of questions referring to anthropometric and demographic data, enquiring about the respondents' age, height, weight and medical conditions.

\section{Research Sample}

The sample was composed of 100 elderly women. The main statistic indicators characterizing the sample are presented in Table 1:

Table 1. Statistic indicators for the main demographic and anthropometric parameters

\begin{tabular}{|c|c|c|c|c|}
\hline & & Height $(\mathrm{cm})$ & Weight (kg) & Age (years) \\
\hline \multirow[t]{2}{*}{$\mathrm{N}$} & Valid & 100 & 100 & 100 \\
\hline & Missing & 0 & 0 & 0 \\
\hline \multicolumn{2}{|c|}{ Mean } & 161.75 & 72.96 & 67.05 \\
\hline \multicolumn{2}{|c|}{ Median } & 163.00 & 71.00 & 64.00 \\
\hline \multicolumn{2}{|c|}{ Mode } & 165 & 80 & 59 \\
\hline \multicolumn{2}{|c|}{ Std. Deviation } & 6.663 & 11.414 & 8.916 \\
\hline \multicolumn{2}{|c|}{ Minimum } & 148 & 50 & 55 \\
\hline \multicolumn{2}{|c|}{ Maximum } & 184 & 112 & 87 \\
\hline
\end{tabular}

Source: SPSS software

The age of the participants varied between 55 to 87 years, with the eldest female subjects (over 71 years) making the most of the sample (34\%), followed by the subjects of the $60-64$ years $(27 \%)$ and $55-59$ years $(26 \%)$ age groups, respectively. The average height of the subjects of the studied sample was $161,75 \mathrm{~cm}$, the average weight was $73 \mathrm{~kg}$ and the average age was 67 years.

\section{DATA ANALYSIS AND INTERPRETATION OF RESEARCH RESULTS}

Statistical processing of collected data used the statistical software SPSS for Windows, version 19.0, and descriptive and inferential statistical analysis was conducted in the following stages: the statistic summary of relevant information and the analysis of variance. In order to investigate the significant variance of the investigated variables, the participants have been divided into three weight groups, as presented in Figure 1:

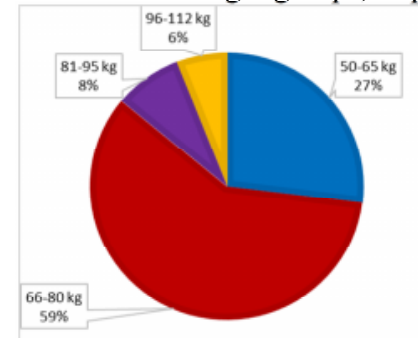

Figure 1. Sample structure by weight 
ICAMS $2016-6^{\text {th }}$ International Conference on Advanced Materials and Systems

\section{The Analysis of Variance}

The authors investigated the variance of the main biomechanical parameters of elderly women across the three weight groups. The most appropriate testing method was considered the One-Way ANOVA, which was performed using the SPSS software. Four working hypotheses were formulated as follows:

$H_{1}$ : There are statistically significant differences between the three weight groups in terms of the travel speed.

$\mathrm{H}_{2}$ : There are statistically significant differences between the three weight groups in terms of the heel strike.

$H_{3}$ : There are statistically significant differences between the three weight groups in terms of the toe - off phase.

$H_{4}$ : There are statistically significant differences between the three weight groups in terms of the support phase.

The null hypotheses stated that there are no differences between the three weight groups in terms of these biomechanical parameters. The results can be consulted in Table 2:

Table 2. One-Way ANOVA test results for the variance of biomechanical parameters across weight groups

\begin{tabular}{|c|c|c|c|c|c|c|}
\hline & & $\begin{array}{l}\text { Sum of } \\
\text { Squares }\end{array}$ & df & $\begin{array}{l}\text { Mean } \\
\text { Square }\end{array}$ & $\mathrm{F}$ & Sig. \\
\hline \multirow[t]{4}{*}{ Travel speed } & Between & ,191 & 3 &, 064 & 1,986 &, 121 \\
\hline & Groups & & & & & \\
\hline & Within Groups & 3,078 & 96 & ,032 & & \\
\hline & Total & 3,269 & 99 & & & \\
\hline \multirow[t]{4}{*}{ Heel strike } & Between & ,000 & 3 & , 000 & 592 & 622 \\
\hline & Groups & & & & & \\
\hline & Within Groups & ,002 & 96 & , 000 & & \\
\hline & Total & ,002 & 99 & & & \\
\hline \multirow[t]{4}{*}{ Toe off phase } & Between & 867 & 3 & ,289 & 4,109 & ,009 \\
\hline & Groups & & & & & \\
\hline & Within Groups & 6,750 & 96 & ,070 & & \\
\hline & Total & 7,616 & 99 & & & \\
\hline \multirow[t]{2}{*}{ Support phase } & Between & ,861 & 3 & ,287 & 4,071 & ,009 \\
\hline & Groups & & & & & \\
\hline
\end{tabular}

Source: SPSS software

As the significance level is $0,121(\mathrm{p}=0,121)$ which is greater than the significance level of 0,05 established for this analysis, hypothesis $\mathrm{H}_{1}$ was rejected. Therefore, the null hypothesis was accepted, stating that there are no statistically significant differences between the three weight groups of elderly women in the investigated sample in terms of the travel speed.

The same decision applies for $\mathrm{H}_{2}$ also $(\mathrm{p}=0,622)$, resulting that there are no statistically significant differences between the three weight groups of women in terms of the heel strike.

The significance level for hypothesis $\mathrm{H}_{3}$ is $0,009(\mathrm{p}=0,009)$, which is smaller than the significance level of 0,05 established for the ANOVA analysis. Hypothesis $\mathrm{H}_{3}$ was 
therefore accepted, confirming that there are statistically significant differences between the three weight groups in terms of the toe off phase. Consequently, the null hypothesis was rejected.

The significance level for hypothesis $\mathrm{H}_{4}$ is also $0,009(\mathrm{p}=0,009)$ smaller than the significance level of 0,05 established for the analysis. This recommends that the working hypothesis $\mathrm{H}_{3}$ should be accepted, confirming that there are statistically significant differences between the three weight groups of elderly women in the investigated sample in terms of the support phase.

As expected, weight is one of the most important factors that causes variations to the biomechanical parameters of elderly women.

\section{CONCLUSIONS}

In this research, the authors conducted a study in order to investigate the variance of various biomechanical parameters of elderly women across three weight groups. Four working hypotheses were formulated and tested using thee One - Way ANOVA test.

Following the testing, the first hypothesis $\mathrm{H}_{1}$ was rejected, determining that there are no statistically significant differences between the three weight groups in terms of the travel speed.

Hypothesis $\mathrm{H}_{2}$ was also rejected, showing that there are no significant differences between the three weight groups of elderly women in the investigated sample in terms of heel strike.

The working hypothesis $\mathrm{H}_{3}$ was accepted, confirming that there are statistically significant differences between the three weight groups of elderly women in the investigated sample in terms of the toe-off phase.

Hypothesis $\mathrm{H}_{4}$ was also accepted, confirming that there are statistically significant differences between the three weight groups of elderly women in the investigated sample in terms of the support phase.

Therefore, weight proved to be an important factor that influences important biomechanical parameters in the case of elderly women. Such biomechanical indicators include the toe off phase and support phase, while the travel speed and heel strike are not affected by the variation of subjects' weight.

\section{Acknowledgements}

This work was supported by UEFISCDI Bucharest under the Partnership Programme project "Preventing gait deficiencies and improving biomechanical parameters for the elderly population by designing and developing customized footwear", acronym MOBILITY, code PN-II-PT-PCCA 2013-4, Contract no. 122/2014.

\section{REFERENCES}

AMTI, Accugait Walkway [Internet], [cited 10th May 2016], available from: www.amti.biz.

Deselnicu, D.C., Vasilescu, A.M., Mihai, A., Purcarea, A.A. and Militaru, G. (2016a), "New Products Development through Customized Design Based on Customers' Needs. Part 1: Footwear Comfort Parameters", Procedia Technology, 22, 1043-1050.

Deselnicu, D.C., Vasilescu, A.M., Mihai, A., Purcarea, A.A. and Militaru, G. (2016b), "New Products Development through Customized Design Based on Customers' Needs. Part 2: Foot Pathology Manufacturing Parameters", Procedia Technology, 22, 1059-1065. 
ICAMS $2016-6^{\text {th }}$ International Conference on Advanced Materials and Systems

Deselnicu, D.C., Vasilescu, A.M., Purcarea, A.A. and Militaru, G. (2014), "Sustainable Consumption and Production in the Footwear Sector", Leather and Footwear Journal, 14(3), 159-180.

Deselnicu, V., Arca, E., Badea, N., Maier, S.S. and Deselnicu, D.C. (2008), "Alternative process for tanning leather", Leather and Footwear Journal, 8(4), 25-34.

Galasso, V., Gatti, R. and Profeta, P. (2009), "Lessons of an aging society; The Political Sustainability of Social Security", Economic Policy, 19, 63-115.

Mihai, A., Curteza, A., Harnagea, F. and Malureanu, G. (2005), "The role of the biomechanics studies in conceiving the performing footwear", Proceedings of the 4th International Conference on the Management of Technological Changes, 281-286.

Vasilescu, A.M., Berijan, G. and Micu, A. (2010), "Analysis of forces causing or restricting movements of the human body", Proceedings of the 3rd International Conference on Advanced Materials and Systems, 331-336.

Zainescu, G., Albu, L., Deselnicu, D.C., Constantinescu, R.R. and Vasilescu, A.M. (2014), "A new concept of complex valorization of leather wastes", Materiale Plastice, 51, 90-93. 
Analysis of Biomechanical Parameters Variance by Weight for Elderly Women in Romania

" 